\title{
Diagnosing the nutritional status of schoolchildren: a comparison between Brazilian and international criteria
}

\author{
Henyse G. Valente da Silva, ${ }^{1}$ Vera Lucia Chiara, ${ }^{2}$ Maria Elisa Barros, ${ }^{3}$ \\ Ana Lúcia Rêgo, ${ }^{4}$ Adriana Ferreira, $^{5}$ Bruna A. Pitasi, $^{6}$ Thaís Mattos $^{6}$
}

\begin{abstract}
Objective: To compare Brazilian and international criteria for assessing the nutritional status of schoolchildren.

Methods: This was a cross-sectional study that enrolled 160 schoolchildren from a public school in the city of Rio de Janeiro, 91 boys and 69 girls, aged 7 to 9 full years. Body mass index (BMI) for sex and age was used to diagnose underweight, healthy weight and overweight, according to Cole et al., Conde \& Monteiro and the World Health Organization (WHO) criteria. Student's $t$ test, the chi-square test, the Kendall concordance test and the chi-square test for tendencies were used to analyze the data; graphs were plotted demonstrating BMI by age, according to the nutritional diagnosis at each set of criteria.
\end{abstract}

Results: Mean BMI did not differ by $\operatorname{sex}(t=0.2845, \mathrm{p}=0.7789)$. According to the first two sets of criteria, none of the children were underweight, whereas, according to the WHO criteria, one of the boys was underweight. The Kendall test did not demonstrate any significant difference between the three sets of criteria (coefficient of concordance for boys was $\mathrm{W}<0.0004$ and for girls it was $\mathrm{W}<0.0008$, with $\mathrm{p}=1.00$ ). There was a greater proportion of assessments that did not agree among the boys, at $15.13 \%$, while for the girls this figure was $13.04 \%$. A significant tendency was observed for the difference between the criteria to increase with age among the boys (chi-square for tendencies = $6.552, p=0.0105$ ), which was evident on the graph and was independent of nutritional status.

Conclusions: The criteria used here converged on the same result, without discrepancies between them or advantages for either. Nevertheless, among the boys there was a significant tendency for the diagnoses to differentiate and BMI to increase with age, which is a warning to take care when choosing among criteria.

J Pediatr (Rio J). 2008;84(6):550-555: Nutritional assessment, nutritional status, diagnostic methods, body mass index, children.

\section{Introduction}

Monitoring nutritional status is important at all ages and is a central axis of healthcare actions aimed at childhood and adolescence. Its importance during these phases of life stems from monitoring the process of growth and development, in order to detect possible health problems and risks of morbidity and mortality, ${ }^{1,2}$ especially with reference to the prevalence of overweight/obesity in Brazil and worldwide. ${ }^{3-5}$

Until recently, the nutritional status of Brazilian children was assessed using the indicators weight/height and height/

1. Doutora. Faculdade de Medicina, Universidade Federal do Rio de Janeiro (UFRJ), Rio de Janeiro, RJ, Brazil.

2. Doutora. Instituto de Medicina Social, UFRJ, Rio de Janeiro, RJ, Brazil.

3. Doutora. Escola Paulista de Medicina, Universidade Federal de São Paulo (UNIFESP-EPM), São Paulo, SP, Brazil.

4. Nutricionista. Mestranda em Alimentação, Nutrição e Saúde, Instituto de Nutrição, UFRJ, Rio de Janeiro, RJ, Brazil.

5. Nutricionista. Mestranda em Ciências da Saúde, Faculdade de Ciências Médicas, UFRJ, Rio de Janeiro, RJ, Brazil.

6. Bolsista FAPERJ. Instituto de Nutrição, Universidade do Estado do Rio de Janeiro (UERJ), Rio de Janeiro, RJ, Brazil.

Financial support: FAPERJ.

No conflicts of interest declared concerning the publication of this article.

Suggested citation: da Silva HG, Chiara VL, Barros ME, Rêgo AL, Ferreira A, Pitasi BA, et al. Diagnosing the nutritional status of schoolchildren: a comparison between Brazilian and international criteria. J Pediatr (Rio J). 2008;84(6):550-555

Manuscript received Jun 17 2008, accepted for publication Oct 102008.

doi:10.2223/JPED.1853 
age, in accordance with World Health Organization (WHO) recommendations. ${ }^{6}$ Over recent decades, different assessment criteria have emerged, and body mass index (BMI), obtained from national studies using distinct methodologies and populations, has been proposed as an indicator. ${ }^{7-11}$

Cole et al. ${ }^{8}$ developed proposals based on national studies carried out in several countries, including the United States, England, Singapore, Hong Kong and Brazil. This nutritional assessment system was recommended by the International Obesity Taskforce for assessment of overweight and obesity in children and adolescents. Later on, the same authors supplemented that research, publishing figures for diagnosing underweight and, consequently, making it possible to determine healthy weight as well. ${ }^{9}$ Within the same area of research, Conde $\&$ Monteiro ${ }^{10}$ recently published a proposal in Brazil presenting new criteria for nutritional assessment of children and adolescents, adopting the same indicator, calculated from anthropometric measurements obtained from a study carried out with the Brazilian population.

In 2007, Onis et al. ${ }^{11}$ published a new reference standard for nutritional assessment of children and adolescents using $\mathrm{BMI}$, based on the $\mathrm{WHO}^{12}$ data from the American population.

This diversity of proposals calls attention to the possibility that different results may be obtained depending on which method is used. Within this context, this study was conducted with the objective of assessing the nutritional status of schoolchildren using three different sets of criteria and of comparing the resulting diagnoses. The criteria chosen were those proposed by Cole et al.., ${ }^{89}$ Conde $\&$ Monteiro ${ }^{10}$ and the WHO. ${ }^{12}$

\section{Methods}

This is a cross-sectional epidemiological study which is the first stage of a larger longitudinal research project with schoolchildren. The underlying project was planned as a cohort study focusing on adolescence, including an initial census phase to establish the nutritional profile of all of the schoolchildren (children and adolescents). In 2007, 1,004 students were enrolled at the school. From this total, 199 schoolchildren $(19.82 \%)$ were lost to the sample. Of these, 76 did not take part because they were in their pre-university year and 123 did not agree to participate. Therefore, the research project included 805 schoolchildren, predominantly adolescents, breaking down into 645 adolescents aged 10 to 19 full years and 160 children aged 7 to 9 years. The population of 160 children aged from 7 to 9 full years was made up of 91 boys and 69 girls. The study variables were: sex, age (years), weight $(\mathrm{kg}$ and $\mathrm{g})$, height $(\mathrm{cm}), \mathrm{BMI}\left(\mathrm{kg} / \mathrm{m}^{2}\right)$ and classification of nutritional status.

Nutritional status was assessed according to age and sex, using BMI with cutoff points defined for underweight, healthy weight and overweight, according to the three proposed sets of criteria.

In order to obtain the full range of criteria proposed by Cole et al., ${ }^{8,9}$ the two publications, from $2000^{8}$ and 2007, ${ }^{9}$ were combined. The BMI figures for underweight were taken from the $17 \mathrm{~kg} / \mathrm{m}^{2}$ column in the 2007 Cole et al. study. ${ }^{9}$ Healthy weight was defined as the BMI values between the $2007,17 \mathrm{~kg} / \mathrm{m}^{2}$ column, ${ }^{9}$ and the $2000,24.9 \mathrm{~kg} / \mathrm{m}^{2} \mathrm{col}-$ umn. ${ }^{8}$ Overweight was defined based on the 2000 publication, ${ }^{8}$ taking the $25 \mathrm{~kg} / \mathrm{m}^{2}$ BMI figures as the cutoff. The cutoff values in the $\mathrm{BMI} / \mathrm{sex} / \mathrm{age}$ columns that were used here can be found in the tables published in the two studies cited. ${ }^{8,9}$

The criteria published by Conde \& Monteiro ${ }^{10}$ defines BMI cutoffs for both underweight and overweight. For the purposes of this study, we defined the interval between the BMI values for underweight (inclusive) and those for overweight (exclusive) as the healthy weight. These values have been published in detail in tabulated format. ${ }^{10}$

The WHO cutoffs were taken from the scale of percentiles on the simplified table published by the $\mathrm{WHO},{ }^{12}$ based on a study carried out by Onis et al. ${ }^{11}$ Underweight was defined as BMI values below the 3rd percentile; healthy weight as those between the 3rd percentile (inclusive) and the 85th percentile (exclusive); and overweight was defined as BMI at or above the 85th percentile.

Body measurements were taken according to standards defined by Lohman et al. ${ }^{13}$ by trained anthropometrists, including undergraduate Nutrition students and graduate students studying healthcare, with the objective of guaranteeing precision and exactness.

Body weight was measured using a portable digital balance, SECA ${ }^{\circledR}$ brand, with the capacity for $150 \mathrm{~kg}$. Height was measured using a $2 \mathrm{~m}$ stadiometer fixed to a wall with no skirting. Children were measured in the orthostatic position, positioned in such a way that the head, shoulders, buttocks and calves touched the smooth wall. Height was measured in duplicate, recorded in $\mathrm{cm}$ and the arithmetic mean of the two used for analysis, with a maximum of $0.1 \mathrm{~cm}$ allowed between the two measurements. In the rare cases in which this value was exceeded, the researcher chosed the measurement chosen as standard. The children were weighed unshod and with light clothing.

Data were analyzed by the following comparisons: mean BMI was compared between sexes using Student's $t$ test; the prevalence rates of each nutritional status diagnosis were compared by applying the chi-square test; and the nutritional classifications made with each criteria, organized ordinally, were compared using Kendall's rank correlation test. The chi-square test for linear tendencies was employed to assess the frequencies of agreement and disagreement between the criteria according to age and sex. The significance level was defined as $p<0.05$ for all tests. Graphs were plotted of median 
Table 1 - Statistical parameters for age, weight, height and BMI, by sex

\begin{tabular}{|c|c|c|c|c|c|c|}
\hline \multirow[b]{2}{*}{ Variables } & \multicolumn{6}{|c|}{ Statistical parameters } \\
\hline & Mean \pm SD & Median & 1st quartile & 3rd quartile & Minimum & Maximum \\
\hline \multicolumn{7}{|l|}{ Boys $(n=91)$} \\
\hline Weight & $32.17 \pm 7.71$ & 30.20 & 26.60 & 36.90 & 21.40 & 56.80 \\
\hline Height (stature) & $131.54 \pm 7.49$ & 131.70 & 126.45 & 135.97 & 117.00 & 151.90 \\
\hline BMI* & $18.40 \pm 3.09$ & 18.03 & 16.15 & 19.89 & 13.68 & 28.37 \\
\hline \multicolumn{7}{|l|}{ Girls $(n=69)$} \\
\hline Weight & $31.75 \pm 7.98$ & 31.00 & 25.40 & 36.80 & 20.80 & 60.80 \\
\hline Height (stature) & $130.10 \pm 7.77$ & 130.35 & 124.30 & 135.20 & 115.40 & 152.80 \\
\hline BMI* & $18.54 \pm 3.16$ & 17.87 & 16.44 & 20.50 & 13.32 & 29.18 \\
\hline
\end{tabular}

$\mathrm{SD}=$ standard deviation; $\mathrm{BMI}=$ body mass index

$* t=0.284$ and $\mathrm{p}=0.778$ (not significant).

BMI according to nutritional status, age and sex for each reference used. For the purposes of the chi-square test and for plotting the curves, the nutritional condition of underweight was combined with the healthy weight sample due to the very low prevalence of underweight children. This group was called "not overweight." The statistical program employed was Epi Info version 3.3.2. ${ }^{14}$

The project was approved without reservations by the Ethics Commission at the Universidade do Estado do Rio de Janeiro, under research protocol number 043.3.2006.

\section{Results}

Mean BMI did not differ significantly between the boys and girls with $t=0.284$ and $\mathrm{p}=0.778$ (Table 1 ).

Neither the criteria proposed by Conde \& Monteiro ${ }^{10}$ nor by Cole et al., ${ }^{9}$ classified any of the children, of either sex, as underweight. The WHO criteria, ${ }^{12}$ in contrast, identified 1 case among the boys. For the whole sample, the prevalence rates of each nutritional status diagnosis did not differ significantly between the different assessment criteria $(p>0.05)$ (Table 2).

In agreement with this result, the analysis of concordance using the Kendall rank correlation test also did not demonstrate any significant difference (coefficient of concordance for boys $=\mathrm{W}<0.0004$, and for girls $=\mathrm{W}<0.0008$, with $\mathrm{p}=$ $1.00)$.

There were 23 cases in which the three criteria did not agree, predominantly among the boys, with $15.13 \%$ of that subset, while $13.04 \%$ of the girls were classified differently by different criteria (Table 3 ).

Analysis of the frequencies of agreement and disagreement observed demonstrated that the number of different

Table 2 - Nutritional status diagnoses of the children, by sex, according to each of the criteria studied

\begin{tabular}{|c|c|c|c|}
\hline Nutritional status* & Cole et al. 8,9 & Conde \& Monteiro ${ }^{10}$ & WHO 12 \\
\hline \multicolumn{4}{|l|}{ Boys $(n=91)^{+}$} \\
\hline Underweight & - & - & 01 \\
\hline Healthy weight & 57 & 53 & 43 \\
\hline Overweight & 34 & 38 & 47 \\
\hline \multicolumn{4}{|l|}{ Girls $(n=69)^{\ddagger}$} \\
\hline Underweight & - & - & - \\
\hline Healthy weight & 40 & 32 & 33 \\
\hline Overweight & 29 & 37 & 36 \\
\hline
\end{tabular}

WHO $=$ World Health Organization.

* Underweight was combined with healthy weight for the chi-square test.

${ }^{+}$Chi-square $=3.96$ and $p=0.265$.

${ }^{*}$ Chi-square $=2.60$ and $p=0.437$. 
Table 3 - Frequencies of agreement and disagreement between the nutritional diagnoses by each criteria, by sex and age

\begin{tabular}{|c|c|c|c|c|c|c|}
\hline \multirow[b]{2}{*}{ Age (years) } & \multicolumn{3}{|c|}{ Boys* } & \multicolumn{3}{|c|}{ Girls $^{+}$} \\
\hline & $\mathbf{n}$ & Agreement & Disagreement & $\mathbf{n}$ & Agreement & Disagreement \\
\hline 7 & 35 & 33 & 2 & 25 & 22 & 3 \\
\hline 8 & 29 & 25 & 4 & 24 & 22 & 2 \\
\hline 9 & 27 & 19 & 8 & 20 & 16 & 4 \\
\hline Total & 91 & 77 & 14 & 69 & 60 & 9 \\
\hline
\end{tabular}

* Chi-square test for linear tendencies $=6.552$ and $p=0.010$ (significant).

${ }^{+}$Chi-square test for linear tendencies $=0.539$ and $p=0.462$ (not significant).

classifications tended to increase significantly in line with age, although only among the boys (chi-square test for tendencies $=6.552$ and $p=0.01$ ). In line with this tendency to diagnose the boys differently, Figure 1 illustrates the median BMI values in the form of lines on a graph against age. The lines diverging with age, both in the "not overweight" group and in the "overweight" group, demonstrate the differences, especially with relation to the WHO criteria. ${ }^{12}$

Boys Not overweight

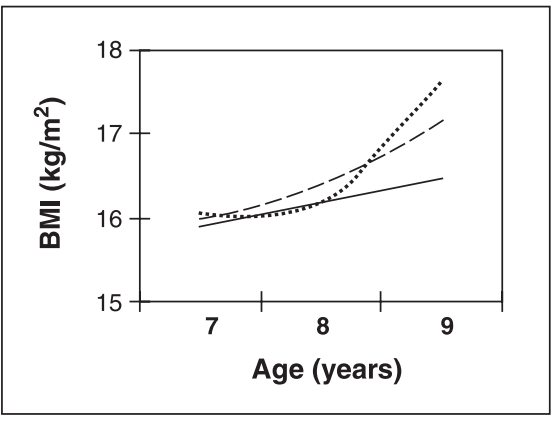

Overweight

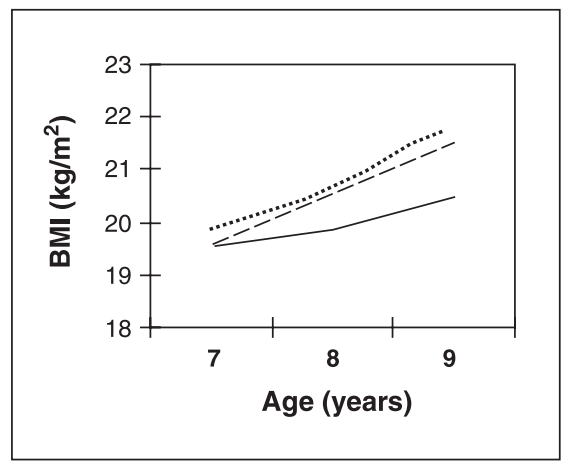

\section{Discussion}

There is not yet consensus on which proposal for nutritional assessment criteria is most appropriate for use with schoolchildren. Discussions continue both on the reference values and the cutoff point that should be used. ${ }^{15-18}$

In a study by O'Neill et al., ${ }^{19}$ with 596 Irish children aged 5 to 12 years, the authors observed an elevated prevalence

\section{Girls}

Not overweight

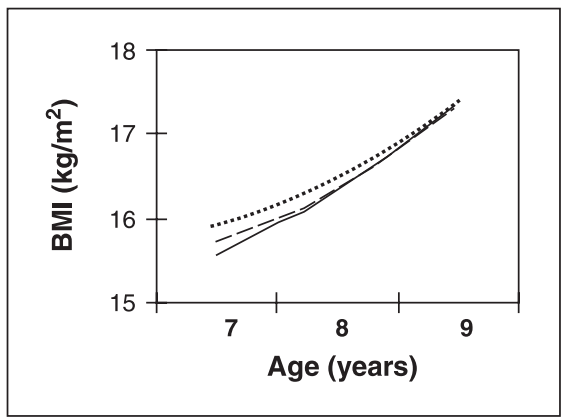

Overweight

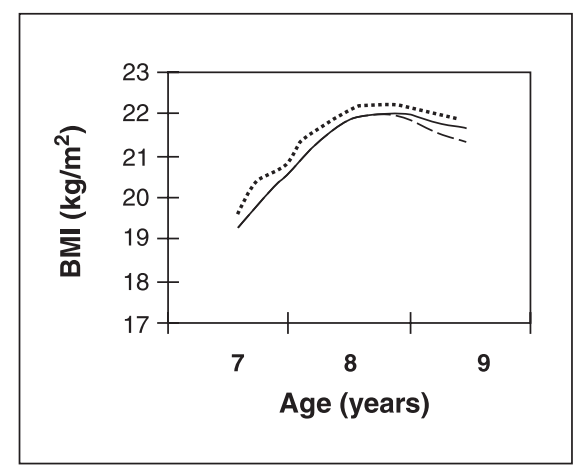

Cole et al. ${ }^{8,9}$

---- Conde \& Monteiro ${ }^{10}$

World Health Organization ${ }^{12}$

Figure 1 - Median body mass index (BMI) of children classed as overweight or not overweight by each set of criteria, by sex 
of obesity/overweight in the entire group, using methods recommended by the Center of Disease Control ${ }^{7}$ a growth curve for the United Kingdom ${ }^{20}$ and the International Obesity Taskforce criteria. ${ }^{8}$

Abrantes et al., ${ }^{21}$ used methods proposed by Cole et al. ${ }^{8}$ and by Must et al. ${ }^{22}$ and performed comparative analyses with 5,736 Brazilian children and adolescents and concluded that the correlation between the two methods was satisfactory.

In a similar manner, our study did not detect significant differences in the prevalence rates of the different nutritional diagnoses of the schoolchildren, comparing proposals published by Cole et al. ${ }^{8,9}$ Conde $\&$ Monteiro ${ }^{10}$ and the WHO, ${ }^{12}$ whether for the nutritional condition of healthy weight or for overweight.

However, a study carried out by Wang \& Wang $^{17}$ which used the criteria proposed by Cole et al. ${ }^{8}$ and Must et al. ${ }^{22}$ only observed similar results for overweight in children and adolescents, leading to the conclusion that greater care must be taken when choosing a method specifically for assessing obesity.

According to Chinn \& Rona, ${ }^{23}$ who compared the criteria proposed by Cole et al. ${ }^{8}$ and Cole et al. ${ }^{20}$ to assess overweight/ obesity in 6,000 English children aged 4 to 11 years, the increase in the prevalence of obesity in the population during the 10 year interval may be the result of the different cutoff points proposed. For these authors, using the United Kingdom criteria, ${ }^{20}$ the prevalence of overweight/obesity increased, with a variation of more than $7 \%$.

Sex and age are also important elements in comparative studies of criteria for nutritional assessment, especially during the late phases of childhood and during adolescence. In this study, although there was not a statistically significant difference in the diagnoses using the three criteria, it was observed that the proportion of disagreement increased systematically with age among the boys. A similar result in terms of differentiation between age and sex was demonstrated in a study by Flegal et al., ${ }^{24}$ who also compared methods for nutritional assessment of children with overweight. These authors observed that, among the boys, the differences between the criteria emerged as age increased.

In a study by Marrodán et al. ${ }^{25}$ in which two different sets of criteria were used for nutritional assessment of 7,228 children and adolescents aged from 6 to 20 years, differences were also observed to emerge as the age of the boys progressed. These authors concluded that the number of obesity cases may be underestimated and the number of overweight children overestimated, depending on the criteria adopted.

In addition to the question of the possible differences between cutoff values for different criteria, there is also a discussion about the use of BMI at the end of childhood and during adolescence. Although this nutritional indicator is widely used with adults, academics suggest caution when applying it to younger populations. ${ }^{26,27}$ This argument is based on the variations in body composition that take place during this period of life, particularly with relation to height, which influences BMI. 26,28

It is known that during the process of growth and development there is very significant growth in height. This, however, differs with age and sex, happening earlier among females. ${ }^{28}$ Therefore, it would be the girls and not the boys that would have a greater biological probability of undergoing changes as a result of prepubescent phase. However, the absence of significant differences in mean BMI between sexes demonstrates that the two groups were similar. Therefore, the tendency for the different criteria to produce different nutritional diagnoses for the boys may well be a result of distinctions within the criteria themselves.

A larger sample per age group and the application of methods considered as reference standards for nutritional assessment with this age group would make it possible to make a more in-depth analysis of this tendency towards differentiation. In this study, the sample was defined by census, stratified by sex and then by age, contributing to dilutions of the sample size at each age. The small number of observations restricts the possibilities of combinations between criteria, which increases the probability that the tendency may have emerged by chance. Greater probability of identifying statistically significant differences is related to the sample size calculation and the error types (I and II) adopted for this calculation. ${ }^{29}$

Based on the results and the issues explored here, it is concluded that these criteria do not differ substantially in the nutritional assessment of schoolchildren. This statement, however, is made in the absence of studies to analyze the age-related differences between sexes in greater detail.

\section{References}

1. Reinehr T, de Sousa G, Andler W. Longitudinal analyses among overweight, insulin resistance, and cardiovascular risk factors in children. Obes Res. 2005;13:1824-33.

2. Papandreou D, Rousso I, Makedou A, Arvanitidou M, Mavromichalis I. Association of blood pressure, obesity and serum homocysteine levels in healthy children. Acta Paediatr. 2007;96:1819-23.

3. Monteiro CA, Conde WL, Popkin BM. Is obesity replacing or adding to undernutrition? Evidence from different social classes in Brazil. Public Health Nutr. 2002;5:105-12.

4. Lobstein T, Baur L, Uauy R; IASO International Obesity TaskForce. Obesity in children and young people: a crisis in public health. Obes Rev. 2004;5 Suppl 1:4-104.

5. Zimmermann MB, Gübeli C, Püntener C, Molinari L. Overweight and obesity in 6-12 year old children in Switzerland. Swiss Med Wkly. 2004;134:523-8.

6. World Health Organization. Physical status, the use and interpretation of anthropometry. WHO Technical Report Series No. 854. Geneva: WHO; 1995. 
7. Kuczmarski RJ, Ogden CL, Grummer-Strawn LM, Flegal KM, Guo SS, Wei R, et al. CDC growth charts: United States. Adv Data. 2000;314:1-27.

8. Cole TJ, Bellizzi MC, Flegal KM, Dietz WH. Establishing a standard definition for child overweight and obesity worldwide: international survey. BMJ. 2000;320:1240-3.

9. Cole TJ, Flegal KM, Nicholls D, Jackson AA. Body mass index cut offs to define thinness in children and adolescents: international survey. BMJ. 2007;335:194. Epub 2007 Jun 25.

10. Conde WL, Monteiro CA. Body mass index cutoff points for evaluation of nutritional status in Brazilian children and adolescents. J Pediatr (Rio J). 2006;82:266-72. Epub 2006 Jul 13.

11. de Onis M, Onyango AW, Borghi E, Siyam A, Nishida C, Siekmann J. Development of a WHO growth reference for school-aged children and adolescents. Bull World Health Organ. 2007;85:660-7.

12. World Health Organization. Growth reference data for 5-19 years. www.who.int/growthref/en/ . Access: 01/10/2007.

13. Lohman TG, Roche AF, Martorell R. Anthropometric standardization reference manual. Illinois: Human Kinetics Books; 1988.

14. Centers for Disease Control and Prevention (CDC). Epi-Info, versão 3.3.2. 2005.

15. Flegal KM, Ogden $C L$, Wei R, Kuczmarski RL, Johnson $C L$. Prevalence of overweight in US children: comparison of US growth charts from the Centers for Disease Control and Prevention with other reference values for body mass index. Am J Clin Nutr. 2001;73:1086-93.

16. Kain J, Uauy R, Vio F, Albala C. Trends in overweight and obesity prevalence in Chilean children: comparison of three definitions. Eur J Clin Nutr. 2002;56:200-4.

17. Wang Y, Wang JQ. A comparison of international references for the assessment of child and adolescent overweight and obesity in different populations. Eur J Clin Nutr. 2002;56 973-82.

18. Butte NF, Garza C, de Onis M. Evaluation of the feasibility of international growth standards for school-aged children and adolescents. Food Nutr Bull. 2006,27 (4 Suppl Growth Standard): S169-74.

19. O'Neill JL, McCarthy SN, Burke SJ, Hannon EM, Kiely M, Flynn A, et al. Prevalence of overweight and obesity in Irish school children, using four different definitions. Eur J Clin Nutr. 2007; 61:743-51. Epub 2006 Dec 20.
20. Cole TJ, Freeman JV, Preece MA. Body mass index reference curve for the UK, 1990. Arch Dis Child. 1995;73:25-9.

21. Abrantes MM, Lamounier JA, Colosimo EA. Comparison of body mass index values proposed by Cole et al. (2000) and Must et al. (1991) for identifying obese children with weight-for-height index recommended by the World Health Organization. Public Health Nutr. 2003;6:307-11.

22. Must A, Dallal GE, Dietz WH. Reference data for obesity: 85th and 95th percentiles of body mass index (wt/ht2) and triceps skinfold thickness. Am J Clin Nutr. 1991;53:839-46.

23. Chinn S, Rona RJ. International definitions of overweight and obesity for children: a lasting solution? Ann Hum Biol. 2002;29: 306-13.

24. Flegal KM, Tabak CJ, Ogden CL. Overweight in children: definitions and interpretation. Health Educ Res. 2006;21: 755-60. Epub 2006 Oct 27.

25. Marrodán Serrano MD, Mesa Santurino MS, Alba Díaz JA, Ambrosio Soblechero B, Barrio Caballero PA, Drak Hernández L, et al. Obesity screening: updated criteria and their clinical and populational validity. An Pediatr (Barc). 2006;65:5-14.

26. Dietz WH, Bellizzi MC. Introduction: the use of body mass index to assess obesity in children. Am J Clin Nutr. 1999;70:123S-5S.

27. Giugliano R, Melo AL. Diagnóstico de sobrepeso e obesidade em escolares: utilização do índice de massa corporal segundo padrão internacional. J Pediatr (Rio J). 2004;80:129-34.

28. Chiara V, Sichieri R, Martins PD. Sensibilidade e especificidade de classificação de sobrepeso em adolescentes, Rio de Janeiro. Rev Saude Publica 2003; 37:226-31.

29. Rodrigues PC. Bioestatística. Niterói, RJ: EdUFF; 2002.

Correspondence:

Henyse Gomes Valente da Silva

Rua Josué de Castro, 39

CEP 22793-265 - Rio de Janeiro, RJ - Brazil

Fax: +55 (21) 3431.3848

E-mail: henysevalente@hotmail.com 